good job with respect to establishing natural areas on federal lands; however, it is evident that there is a need to develop a cooperative program with state and private agencies so that those ecological types which are not found on federal lands will be preserved in an integrated program. Similarly, in Canada, there is a need for integrated natural area program; the IBP-CT and some of the provinces have made good headway and it is anticipated that the Canadian Institute of Forestry will develop a program which will complement those already in progress. (See also the article by Roche in this issue.)

J. H. Cayford

\section{Pesticides}

A 16-page booklet, Pesticides and the environment, available from the Canadian Agricultural Chemicals Association, 1010 St. Catherine St. W., Montreal 110, is concerned with defining the nature and cause of the chemical/environment problem. Amongst other items, the booklet describes briefly the regulation and control of pesticides.

\title{
Perils and protection of packaged lumber
}

Practically all of the three billion board feet of B.C. lumber shipped by water in 1968 was unseasoned and carried in packages as single length, tightly bound units. In this form, no appreciable drying can take place in the wood and thus the risk of fungal deterioration, sap stain, mould and decay is increased with storage time.

Capacity of ships now in use often exceeds 15 million board feet. Because of the time required to manufacture this bulk of material and to transport it to and from a ship, a period of up to six months may elapse between packaging at a sawmill and arrival at an overseas building site. During this period, unless lumber has been treated or unless the lumber is seasoned, fungal growth can be expected.

Seasoning of lumber to a moisture content below the $20 \%$ level is the most reliable protective measure. Dry lumber costs more and must be covered against precipitation so that, to date, customer demand has not justified the additional costs involved for widespread adoption of the process for waterborne shipments.

Chemical treatment of lumber against sap stain and mould is effective provided it is applied thoroughly. Dipping piece by piece or in bulk is most dependable. Spray applications are effective if they "drench treat" and if they are closely supervised to ensure uniform flow.

Studies at the Western Forest Products Laboratory indicate that, for adequate protection of unseasoned lumber in packages for periods of six months to a year, commercial formulations now in use (containing sodium tetrachlorophenate and various organo-metallic fungicides) should be applied at concentrations of approximately $0.5 \%$ sodium tetrachlorophenate in water dip for rough sawn lumber and at least $0.75 \%$ for planed lumber. These treatments should result in a toxic retention in excess of $0.07 \% \mathrm{w} / \mathrm{w}$ tetrachlorophenol in wood.

Lumber must be fungus free before this treatment, since the chemical can only protect the wood surface; it does not penetrate to any

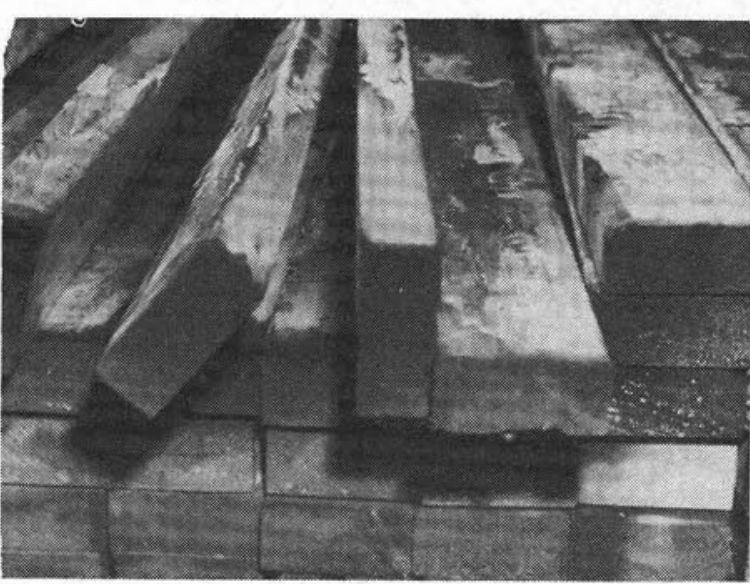

Decay spreading in unseasoned packaged lumber.

degree and cannot guarantee prevention of stain or decay which may be present inside the wood. Infection of this sort may ultimately develop throughout a package, in spite of antistain treatment.

A treatment which promises to prevent decay development in packaged, unseasoned lumber makes use of boron salts which are clean and non-toxic to humans. Lumber is immersed in bulk or piece by piece for several minutes in a hot solution which includes a fungicide protecting against sap stain and mould. Afterwards, the material is stored under cover for six to ten weeks during which time the salt diffuses throughout the wood.

In a laboratory-supervised test where partially decayed western hemlock lumber was employed, the diffusion treatment completely inhibited further rot development in wood over a 12-month period of packaged storage. Retention was 0.2 to $0.3 \mathrm{lb} / \mathrm{ft}^{3}$ boric acid equivalent.

Lumber treated in this way is also protected against subsequent decay or insect attack in service, providing it is not subject to heavy rain or in contact with ground.

J. W. Roff

Department of the Environment Western Forest Products Laboratory Vancouver, B.C. 